\title{
Physical activity and sedentary behaviour and their associations with clinical measures in axial spondyloarthritis
}

\author{
Elaine H. Coulter $^{1}$ (D) Marie Therese McDonald ${ }^{1,2,4}$ (D) Sara Cameron $^{3} \cdot$ Stefan Siebert $^{4}$ (D) Lorna Paul $^{1}$ (D)
}

Received: 10 September 2019 / Accepted: 9 December 2019 / Published online: 17 December 2019

(c) The Author(s) 2019

\begin{abstract}
Engaging in physical activity (PA) is a key aspect in the management of axial spondyloarthritis (axial SpA), however, its relationship with clinical measures is unknown. Previous research has mainly focused on subjective methods of measuring PA and sedentary behaviour (SB). The aim of this study was to explore the associations between objectively measured PA and SB with clinical measures in people with established axial SpA. Fifty participants were recruited from secondary-care rheumatology outpatient services in Glasgow, UK. Clinical measures collected included; Bath Ankylosing Spondylitis Disease Activity Index (BASDAI), Bath Ankylosing Spondylitis Functional Index (BASFI), Bath Ankylosing Spondylitis Metrology Index (BASMI), Ankylosing Spondylitis Quality of Life (ASQOL) and the Six Minute Walk Test (6MWT). PA and SB were measured using the activPAL3 tri-axial accelerometer. Data from forty-five participants were included (23 males, average age $49 \pm 12$ years). Participants accumulated an average of $93.2 \pm 41.5 \mathrm{~min} /$ day walking with an average of $7200 \pm 3397$ steps/day. The majority of the day $(65 \%)$ was spent sitting, accumulated in prolonged bouts. Walking time and steps taken/day were associated with better BASFI $(r=-0.395, p=0.007$ and $r=-0.404, p=0.006)$, ASQOL $(r=-0.375$, $p=0.011$ and $r=-0.361, p=0.015)$ and 6MWT $(r=0.396, p=0.007$ and $r=0.421, p=0.004)$; while longer walking events were associated with better BASMI (rho $=-0.352, p=0.018$ ), BASFI (rho $=-0.316, p=0.034)$ and $6 \mathrm{MWT}($ rho $=0.404$, $p=0.006)$. SB was associated with worse ASQOL $(r=0.380, p=0.010)$ and 6MWT $(6 \mathrm{MWT}, r=-0.357, p=0.016)$. In people with axial SpA PA is associated with better function, exercise capacity and spinal mobility, while SB is associated with lower exercise capacity and poor quality of life. These findings support the promotion of PA and reduction of SB in people with axial SpA.
\end{abstract}

Keywords Axial spondyloarthritis $\cdot$ Physical activity $\cdot$ Sedentary behaviour $\cdot$ Rheumatology

\section{Introduction}

Axial spondyloarthritis (axial SpA), including ankylosing spondylitis and non-radiographic axial SpA, is a chronic inflammatory arthritis characterised by reduced spinal mobility and function and an increased risk of cardiovascular

Marie Therese McDonald

MarieTherese.McDonald@gcu.ac.uk

Elaine H. Coulter

Elaine.Coulter@gcu.ac.uk

Sara Cameron

SarafCameron@gmail.com

Stefan Siebert

Stefan.Siebert@glasgow.ac.uk

Lorna Paul

Lorna.Paul@gcu.ac.uk events [1,2]. A combination of pharmacological and nonpharmacological management is essential for good clinical outcomes in axial SpA. Physical activity (PA) and exercise, a subcategory of PA, are key aspects in the management of people with axial SpA [3, 4]. People with axial SpA are at increased risk of cardiovascular disease [5]. A lack of PA
School of Health and Life Sciences, Glasgow Caledonian University, Cowcaddens Road, Glasgow, UK

2 Rheumatology Service, Queen Elizabeth University Hospital, NHS Greater Glasgow and Clyde, Glasgow, UK

3 School of Medicine, Dentistry and Nursing, University of Glasgow, Oakfield Avenue, Glasgow, UK

4 Institute of Infection, Immunity and Inflammation, University of Glasgow, Sir Graeme Davies Building, University Place, Glasgow, UK 
and predominance of sedentary behaviour (SB), are independent risk factors for co-morbidities, such as cardiovascular disease, in the general population [6] and, therefore, should be considered in axial SpA symptom and co-morbidity management.

Recently, disease activity was found to be associated with time spent sedentary while no association was found with moderate-vigorous physical activity (MVPA) in people with axial SpA [7]. In addition, physical fitness components (aerobic capacity, strength and body fat percentage) were associated with functional ability $[8,9]$ and disease activity [10]. Yet, the relationship between PA and/or SB with clinical measures such as spinal mobility, functional ability and exercise capacity in people with axial SpA is unknown. It is widely considered that people with axial SpA are less active and more sedentary than their healthy counterparts [11]. However, previous research has mainly focused on subjective methods of measuring PA and SB [11] and so may not be an accurate reflection [12]. While self-report measures are convenient and inexpensive, they are subject to issues such as recall bias and social desirability. Agreement between commonly used questionnaires to measure PA and SB has been found to be poor [12,13]. For instance, the International Physical Activity Questionnaire (IPAQ) underestimated sitting time by up to $4.6 \mathrm{~h}$ per day [12]. Therefore, the effects of PA and SB variables on health-related outcomes may be diminished when using inaccurate measurement tools [14]. The aim of this study was to explore the associations between objectively measured PA and SB with axial SpA clinical measures.

\section{Methods}

\section{Study design and participants}

This study utilises baseline data from a prospective cohort study on web-based physiotherapy exercise, which recruited 50 people with axial SpA with low self-reported exercise levels (ClinicalTrials.gov ref: NCT02666313) [15]. The participants were recruited from the secondary-care rheumatology outpatient service of NHS Greater Glasgow \& Clyde, UK. Participants were included if they had a confirmed diagnosis, by a rheumatology consultant, according to the Assessment of Spondyloarthritis International Society criteria [16], for more than one year, were over 18 years and had access to the internet at home. Participants were excluded if they self-reported participating in structured exercise regularly (three or more times per week), had a joint replacement within the last six months, had any significant comorbidities that would preclude them from taking part in a regular exercise programme or if they were currently participating in another clinical trial [15]. All participants gave informed, written consent and the study was approved by the West of Scotland Research Ethics Committee (Ref: 15/WS/0229).

\section{Measurement of physical activity and sedentary behaviour}

PA, defined as any bodily movement produced by skeletal muscle that requires energy expenditure [17], and SB, defined as any waking behaviour characterised by an energy expenditure of $\leq 1.5$ metabolic equivalents while in a sitting, reclining or lying position [18], were objectively measured using the activPAL3 activity monitor (PAL Technologies Ltd, Glasgow, UK). The activPAL3 device is a small, lightweight $(55 \times 35 \times 7 \mathrm{~mm}, 15 \mathrm{~g})$ tri-axial accelerometer worn on the anterior thigh of the dominant leg and attached using a Tegaderm waterproof dressing. The activPAL3 has been found to be a valid measure of steps, walking and sedentary time in healthy adults [19-21]. Participants were asked to wear the monitor continuously for one week and undertake their usual activities. A day was considered valid if it contained $24 \mathrm{~h}$ of wear time. For each participant the time spent standing, walking, number of steps and time spent sedentary per day were measured. Participants were asked to record their sleep time each night using a sleep diary, and sleep time was removed from the analysis [22].

\section{Demographic variables and outcome measures}

Demographic characteristics including age, gender, work status and medication history were collected. Clinical measures included the following, described in full in Paul et al. [15]: Bath Ankylosing Spondylitis Disease Activity Index (BASDAI), a six item questionnaire measuring disease activity with higher scores indicating greater activity [23], Bath Ankylosing Spondylitis Functional Index (BASFI), a 10 item questionnaire measuring functional ability with higher scores indicating worse function [24], Bath Ankylosing Spondylitis Metrology Index (BASMI), a five item index measuring spinal mobility with higher scores indicating greater limitations in movement [25], Ankylosing Spondylitis Quality of Life (ASQOL), a questionnaire with higher scores indicating poorer quality of life [26], and the Six Minute Walk Test (6MWT), a walking test conducted over six minutes with a greater distance walked indicating better exercise capacity [27].

\section{Statistical analysis}

PA and SB data were extracted from the activPAL3 monitors using proprietary software (version 7.24, PAL Technologies, Glasgow, UK). Data were visually inspected hour by hour and compared to completed sleep diaries to ensure accuracy of completed diaries. Additional data processing 
(after activity classification by proprietary software) was conducted to remove sleep time using the HSC analysis program (Version 15.32, Microsoft Excel, Microsoft Corporation, Redmond, WA, USA). A cadence of 100 steps/minute or above was used to represent time spent in MVPA [28, 29] and sitting events of $30 \mathrm{~min}$ or longer were used to define prolonged sitting [30, 31]. Data analysis was performed using SPSS version 25.0 (SPSS, IBM Corp, Armonk, NY, USA). Descriptive statistics were calculated to summarise all outcomes. All outcomes were assessed for normality using the Kolmogorov Smirnov test. Correlations between PA and SB with the BASFI, BASMI, BASDAI, ASQOL, and 6MWT were assessed using Pearson's correlation coefficient if normally distributed. Where data were not normally distributed, Spearman's Rho correlation was used. Correlations of $\geq 0.30, \geq 0.50$ and $\geq 0.70$ were considered small, moderate and large, respectively [32]. The level of significance was set at $5 \%$.

\section{Results}

Fifty participants were recruited between December 2016 and December 2017. PA and SB data were missing for five participants [allergy to Tegaderm dressing $(n=1)$, instrument error $(n=3)$ and researcher error $(n=1)]$; therefore, complete data were available for 45 participants. Complete activPAL3 data for seven $(n=1)$, six $(n=42)$, five $(n=1)$ and four days $(n=1)$ was available. Participants, 23 male and 22 female, had an average age of $49 \pm 12$ years and an average axial $\mathrm{SpA}$ disease duration of $16 \pm 11$ years (Table 1). The majority of participants (69\%) were in paid employment with only $8 \%$ currently receiving physiotherapy treatment or attending an exercise class. Participants had an average BASDAI score of $4.5 \pm 2.3$, of which 28 participants had a BASDAI of $\geq 4$, indicating active disease activity [33] (Table 1). Distance walked during the 6MWT was $414 \pm 106 \mathrm{~m}$ [range 121-622], substantially lower than the reference standard for healthy adults $(571 \pm 90 \mathrm{~m}$ [range 380-782 m]) [34] (Table 1).

Participants walked on average for $93.2 \pm 41.5 \mathrm{~min} /$ day with an average of $7200 \pm 3397$ steps/day and average cadence of $69.6 \pm 4.6 \mathrm{steps} / \mathrm{min}$ (Table 2 ). Approximately $20 \pm 4 \mathrm{~min} /$ day were spent stepping at a moderate intensity (>100 steps/min). The majority of the waking day (65\%) was spent sitting $(10.8 \pm 2.3 \mathrm{~h} /$ day $)$. The majority of the total sitting time ( $40 \% \pm 18 \%$ of the waking day) was accumulated in prolonged bouts (defined as sitting events $\geq 30 \mathrm{~min}$ ) with an average of $6.7 \pm 2.9 \mathrm{~h} /$ day of prolonged sitting bouts. On average, participants accumulated $121 \pm 97 \mathrm{~min} /$ week of PA at a moderate intensity, with one third $(n=15)$ of participants achieving the PA guidelines of $150 \mathrm{~min} /$ week of moderate intensity PA [35]. While there were no statistically
Table 1 Participant characteristics

\begin{tabular}{|c|c|c|}
\hline & $n(\%)$ & Mean \pm SD (range) \\
\hline \multicolumn{3}{|l|}{ Demographics } \\
\hline Age (years) & & $49.0 \pm 11.7(25-79)$ \\
\hline Gender (M:F) & $23: 22$ & \\
\hline Duration of diagnosis (years) & & $15.6 \pm 11.2(1-45)$ \\
\hline $\operatorname{BMI}\left(\mathrm{kg} / \mathrm{m}^{2}\right)$ & & $27.4 \pm 5.6(17.3-41.6)$ \\
\hline \multicolumn{3}{|l|}{ Work status } \\
\hline Paid employment & $31(69 \%)$ & \\
\hline Retired/medically retired & $9(20 \%)$ & \\
\hline Unemployed & $3(7 \%)$ & \\
\hline Off work & $1(2 \%)$ & \\
\hline Student & $1(2 \%)$ & \\
\hline \multicolumn{3}{|l|}{ Current treatment } \\
\hline Anti-TNF & $25(50 \%)$ & \\
\hline NSAIDs & $30(60 \%)$ & \\
\hline Pain relief & $22(44 \%)$ & \\
\hline Physio/exercise class & $4(8 \%)$ & \\
\hline \multicolumn{3}{|l|}{ Disease activity/mobility/function } \\
\hline BASDAI (0-10) & & $4.5 \pm 2.3(0.4-8.7)$ \\
\hline $\begin{array}{l}\text { Low disease activity (BAS- } \\
\text { DAI <4) }\end{array}$ & $17(38 \%)$ & \\
\hline $\begin{array}{l}\text { Active disease activity (BAS- } \\
\text { DAI } \geq 4 \text { ) }\end{array}$ & $28(62 \%)$ & \\
\hline BASMI $(0-10)$ & & $3.6 \pm 1.8(0.4-7.5)$ \\
\hline BASFI (0-10) & & $4.4 \pm 2.6(0.4-9.3)$ \\
\hline \multicolumn{3}{|l|}{ Exercise capacity } \\
\hline 6 min walk test $(\mathrm{m})$ & & $414 \pm 106(121-622)$ \\
\hline
\end{tabular}

$n$ number, $S D$ standard deviation, $m$ metres, $M$ male, $F$ female, $B M I$ Body Mass Index, TNF Tumour Necrosis Factor, NSAIDs Non-Steroidal Anti-Inflammatory Drugs, BASDAI Bath Ankylosing Spondylitis Disease Activity Index, BASMI Bath Ankylosing Spondylitis Metrology Index, BASFI Bath Ankylosing Spondylitis Functional Index

significant differences between those with low and active disease activity (BASDAI), there was a trend for those with active disease activity to be less physically active and more sedentary (Table 2). There were no correlations of age and gender with any PA and SB outcomes.

There were small significant correlations for walking time and steps taken/day with the BASFI, indicating that both time spent walking and steps taken were associated with better function ability (BASFI, $r=-0.395, p=0.007$ and $r=-0.404, p=0.006$, respectively). Similar significant correlations were found for exercise capacity and walking time with steps taken/day (6MWT, $r=0.396$, $p=0.007$ and $r=0.421, p=0.004$, respectively) and quality of life (ASQOL, $r=-0.375, p=0.011$ and $r=-0.361$, $p=0.015$, respectively) (Table 3 ). In addition, time spent in MVPA was associated with better functional ability (BASFI, rho $=-0.358, p=0.016$ ) and exercise capacity 
Table 2 Physical activity and sedentary behaviour outcomes for all participants and those categorised with low and active disease activity

\begin{tabular}{|c|c|c|c|}
\hline & $\begin{array}{l}\text { All participants } n=45 \\
\text { (\% of waking hours) }\end{array}$ & $\begin{array}{l}\text { Low disease activity (BAS- } \\
\text { DAI }<4) n=17 \text { ( } \% \text { of waking } \\
\text { hours) }\end{array}$ & $\begin{array}{l}\text { Active disease activity (BAS- } \\
\text { DAI } \geq 4) n=28 \text { ( } \% \text { of waking } \\
\text { hours) }\end{array}$ \\
\hline Waking hours (hrs) & $16.6 \pm 1.4$ & $16.4 \pm 1.0$ & $16.7 \pm 1.6$ \\
\hline Sleep hours (hrs) & $7.4 \pm 1.4$ & $7.6 \pm 1.0$ & $7.3 \pm 1.6$ \\
\hline Walking duration (mins/day) & $93.2 \pm 41.5(9 \pm 4 \%)$ & $98.6 \pm 39.6(10 \pm 4 \%)$ & $90.0 \pm 43.0(9 \pm 4 \%)$ \\
\hline Standing duration (hrs/day) & $4.2 \pm 1.7(26 \pm 10 \%)$ & $4.4 \pm 1.5(27 \pm 9 \%)$ & $4.2 \pm 1.9(25 \pm 11 \%)$ \\
\hline Sitting duration (hrs/day) & $10.8 \pm 2.3(65 \pm 13 \%)$ & $10.4 \pm 1.7(63 \pm 12 \%)$ & $11.1 \pm 2.6(66 \pm 14 \%)$ \\
\hline Steps/day & $7200 \pm 3397$ & $7615 \pm 3212$ & $6948 \pm 3538$ \\
\hline Steps/hour & $436 \pm 203$ & $462 \pm 192$ & $419 \pm 212$ \\
\hline Walking duration at $>100$ steps/min (mins/day) & $20.3 \pm 16.0$ & $21.5 \pm 15.7$ & $19.6 \pm 16.4$ \\
\hline Mean steps/walking event & $18.5 \pm 6.2$ & $18.1 \pm 5.1$ & $18.7 \pm 6.9$ \\
\hline Mean walking event cadence (steps/min) & $69.6 \pm 4.6$ & $70.1 \pm 5.4$ & $69.3 \pm 4.1$ \\
\hline Mean MVPA (mins/week) & $121 \pm 97$ & $128.9 \pm 94.6$ & $115.9 \pm 99.1$ \\
\hline Participants $\geq 150$ mins of MVPA $(n)$ & $15 / 45$ & $7 / 17$ & $8 / 28$ \\
\hline Sitting events ( $n /$ day) & $49.1 \pm 17.2$ & $48.0 \pm 14.7$ & $49.8 \pm 18.7$ \\
\hline Prolonged sitting events $>30 \mathrm{~min}$ ( $n /$ day $)$ & $6.0 \pm 2.0$ & $5.8 \pm 1.7$ & $6.1 \pm 2.1$ \\
\hline Total duration of prolonged sitting $>30 \mathrm{~min}$ (h/day) & $6.7 \pm 2.9(40 \pm 18 \%)$ & $6.3 \pm 2.4(38 \pm 17 \%)$ & $6.9 \pm 3.2(40 \pm 17 \%)$ \\
\hline
\end{tabular}

$n$ number, hrs hours, mins minutes, MVPA Moderate-Vigorous Physical Activity

Table 3 Correlations between physical activity and sedentary behaviour with axial spondyloarthritis clinical measures

\begin{tabular}{|c|c|c|c|c|c|c|}
\hline Variable & & BASDAI & BASMI & BASFI & ASQOL & 6MWT \\
\hline \multirow[t]{2}{*}{ Sleep hours } & $r$ & -0.65 & 0.115 & -0.001 & -0.061 & -0.146 \\
\hline & $p$ & 0.671 & 0.453 & 0.993 & 0.691 & 0.340 \\
\hline \multirow[t]{2}{*}{ Walking time } & $r$ & -0.162 & -0.197 & -0.395 & -0.375 & 0.396 \\
\hline & $p$ & 0.288 & 0.195 & 0.007 & 0.011 & 0.007 \\
\hline \multirow[t]{2}{*}{ Steps taken } & $r$ & -0.167 & -0.220 & -0.404 & -0.361 & 0.421 \\
\hline & $p$ & 0.272 & 0.147 & 0.006 & 0.015 & 0.004 \\
\hline \multirow[t]{2}{*}{ Stand time } & $r$ & -0.111 & -0.077 & -0.200 & -0.305 & 0.278 \\
\hline & $p$ & 0.468 & 0.617 & 0.188 & 0.042 & 0.065 \\
\hline \multirow[t]{2}{*}{ MVPA mins } & $r$ & -0.189 & -0.235 & -0.358 & -0.254 & 0.451 \\
\hline & $p$ & 0.213 & 0.120 & 0.016 & 0.092 & 0.002 \\
\hline \multirow[t]{2}{*}{ Duration of walking events } & $r$ & -0.058 & -0.352 & -0.316 & -0.095 & 0.404 \\
\hline & $p$ & 0.707 & 0.018 & $\mathbf{0 . 0 3 4}$ & 0.536 & 0.006 \\
\hline \multirow[t]{2}{*}{ Cadence of walking event } & $r$ & -0.125 & -0.040 & -0.063 & 0.085 & 0.130 \\
\hline & $p$ & 0.412 & 0.796 & 0.681 & 0.579 & 0.393 \\
\hline \multirow[t]{2}{*}{ Sitting time } & $r$ & 0.180 & 0.048 & 0.289 & 0.380 & -0.235 \\
\hline & $p$ & 0.236 & 0.796 & 0.054 & 0.010 & 0.120 \\
\hline \multirow{2}{*}{$\begin{array}{l}\text { Prolonged sitting event dura- } \\
\text { tion }(>30 \mathrm{~min})\end{array}$} & $r$ & 0.100 & 0.010 & 0.280 & 0.294 & -0.357 \\
\hline & $p$ & 0.513 & 0.950 & 0.062 & 0.050 & 0.016 \\
\hline
\end{tabular}

The bold indicates associations with corresponding $p$ value of less than or equal to 0.05

BASDAI Bath Ankylosing Spondylitis Disease Activity Index, BASMI Bath Ankylosing Spondylitis Metrology Index, BASFI Bath Ankylosing Spondylitis Functional Index, ASQOL Ankylosing Spondylitis Quality of Life, $6 M W T$ Six Minute Walk Test, MVPA Moderate-Vigorous Physical Activity, mins minutes
(6MWT, rho $=0.451, p=0.002)$. Longer walking events were associated with better spinal mobility (BASMI, rho $=-0.352, p=0.018$ ), functional ability (BASFI, rho $=-0.316, p=0.034)$ and exercise capacity (6MWT, rho $=0.404, p=0.006$ ) (Table 3). Furthermore, greater total time spent sitting was associated with poorer quality of life (ASQOL, $r=0.380, p=0.010$ ) and prolonged sitting was associated with reduced exercise capacity (6MWT, $r=-0.357, p=0.016$ ) (Table 3). 


\section{Discussion}

The results of this study indicate that, in people with axial SpA, higher levels of objectively measured PA (walking time, steps taken, MVPA, duration of walking events) is associated with better functional ability (BASFI), exercise capacity (6MWT) and spinal mobility (BASMI); while higher levels of objectively measured SB (greater total sitting time and prolonged sitting) is associated with reduced exercise capacity (6MWT) and quality of life (ASQoL). While there was no association between SB or PA with disease activity (BASDAI). In this study, monitors were worn continuously which allowed for 24-h assessment which minimised data loss due to compliance or issues in identifying wear time [36]. Furthermore, the activPAL3 is recognised as the gold standard measurement device for postural SB [20, 21], with sleep time, identified using diaries, removed from analysis. This method was of particular benefit as it avoided issues with differentiating between sleep, SB or non-wear time that may occur with other devices [36].

Participants with axial SpA in the current study engaged in a greater amount of SB $(10.8 \pm 2.3 \mathrm{~h} /$ day $)$ than reported in previous research $(7.5 \pm 1.97 \mathrm{~h} /$ day $)$ [7]. Swinnen et al. reported that people with axial SpA were sedentary for $17.99 \mathrm{~h} /$ day including sleep time. If we assume sleep time of approximately $8 \mathrm{~h} /$ day then sedentary time in the current study may be comparable. Participants in the current study spent less time spent in MVPA, $20.3 \pm 16.0 \mathrm{~min} /$ day, compared to $59.1 \pm 29.6 \mathrm{~min} /$ day [7] and $98 \mathrm{~min} /$ day [37]. These differences are likely due to differences in recruitment (participants in the current study were excluded if they selfreported as exercising $\geq 3$ times/week), while differences in measurement device and their position on the body or classification of MVPA may further play a role. For instance, O'Dwyer et al. [7] utilised the RT3 tri-axial accelerometer, worn at the hip for at least $10 \mathrm{~h}$ per day, removed during sleep and washing/bathing activities, providing an output expressed as activity counts and converted to minutes. This could have led to a systematic error in which SB was not consistently measured. Comparisons with other research [38-40], which only reported activity counts, cannot be made since they are arbitrary units which require calibration [40].

Participants in the current study undertook $7200 \pm 3397$ steps/day with only $33 \%$ of participants meeting the current UK and USA PA guidelines (150 mins MVPA/week) [35, 41]. This is similar to previous objectively measured findings (27-39\%) [7, 42], yet lower compared to studies which measured PA participation using questionnaires (41-71\%) [43-45], suggesting participants may overestimate their PA levels when assessed by self-report. This rate of attainment is based upon PA guidelines for healthy adults (18-65 years old) since no disease-specific guidelines exist.
Engaging in regular PA and reducing prolonged $\mathrm{SB}$ is important to maintain and improve health [46]. This study adds to the current literature on PA and SB levels of people with axial SpA using accurate objectively measured PA and $\mathrm{SB}$ in people with axial SpA who self-report as not adhering to PA guidelines. The low adherence to the PA guidelines are concerning given the findings of the current study, risk of developing co-morbidities [5] and the beneficial effects of exercise [3]. The management of people with axial SpA should focus on interventions to improve PA to optimise the health benefit, and consider interventions to reduce SB.

This study has a number of limitations. First, selection bias may be present since studies investigating exercise and PA are likely to recruit participants who are interested in PA/exercise; while, potential participants recruited in the current study were excluded if they were exercising three or more times per week [15]. As such, the PA and SB levels presented may not be representative of the overall axial SpA population. Finally, the results presented are cross-sectional, therefore, prevent determination of causality with multiple comparisons conducted on a small sample with no statistical corrections employed.

\section{Conclusion}

The results demonstrate objective PA outcomes are associated with better function (BASFI), exercise capacity (6MWT) and spinal mobility (BASMI), while SB outcomes are associated with exercise capacity (6MWT) and quality of life (ASQoL) in people with axial SpA. These findings appear to support the promotion of PA and reduction of SB in this population, as well as the use of objective measurement devices for PA and SB in axial SpA. Future research is required to explore if interventions which improve $\mathrm{PA}$ and/ or SB result in improvements in clinical measures.

Acknowledgements We would like to thank the participants who took part in the study. Thanks to Dr Philippa Dall and Professor Malcolm Granat who developed the HSC analysis program. This study was funded by Versus Arthritis (Grant number 20874).

Author contributions All authors contributed to the study conception and design. Material preparation, data collection and analysis were performed by Marie Therese McDonald, Sara Cameron, and Elaine Coulter. The first draft of the manuscript was written by Elaine Coulter and all authors commented on previous versions of the manuscript. All authors read and approved the final manuscript.

\section{Compliance with ethical standards}

Conflict of interest Dr Coulter, Ms McDonald, Dr Siebert and Professor Paul received a research grant from Versus Arthritis (formally Arthritis Research UK) during the conduct of the study. Ms Cameron declares no conflicts of interest. 
Open Access This article is licensed under a Creative Commons Attribution 4.0 International License, which permits any non-commercial use, sharing, adaptation, distribution and reproduction in any medium or format, as long as you give appropriate credit to the original author(s) and the source, provide a link to the Creative Commons licence, and indicate if changes were made. The images or other third party material in this article are included in the article's Creative Commons licence, unless indicated otherwise in a credit line to the material. If material is not included in the article's Creative Commons licence and your intended use is not permitted by statutory regulation or exceeds the permitted use, you will need to obtain permission directly from the copyright holder. To view a copy of this licence, visit http://creativecommons.org/licenses/by-nc/4.0/.

\section{References}

1. Bengtsson K, Elia HF, Lie E, Klingberg E, Dehlin M, Exarchou $S$ et al (2017) Are ankylosing spondylitis, psoriatic arthritis and undifferentiated spondyloarthritis associated with an increased risk of cardiovascular events? A prospective nationwide population-based cohort study. Arthritis Res Ther 19:1-12

2. Dougados M, Baeten D (2011) Spondyloarthritis. Lancet $377: 2127-2137$

3. Regel A, Sepriano A, Baraliakos X, Van Der HD, Braun J, Landewé R et al (2017) Efficacy and safety of pharmacological treatment: a systematic literature review informing the 2016 update of the ASAS / EULAR recommendations for the management of axial spondyloarthritis. RMD Open 3:e000397

4. Dagfinrud H, Hagen KB, Kvien TK (2008) Physiotherapy interventions for ankylosing spondylitis. Cochrane Database Syst Rev

5. Papagoras C, Voulgari PV, Drosos AA (2013) Review Atherosclerosis and cardiovascular disease in the spondyloarthritides, particularly ankylosing spondylitis and psoriatic arthritis. Clin Exp Rheumatol 31:612-620

6. Wilmot EG, Edwardson CL, Achana FA, Davies MJ, Gorely T, Gray LJ et al (2012) Sedentary time in adults and the association with diabetes, cardiovascular disease and death: systematic review and meta-analysis. Diabetologia 55:2895-2905

7. O'Dwyer T, Shea FO, Wilson F (2015) Decreased physical activity and cardiorespiratory fitness in adults with ankylosing spondylitis: a cross - sectional controlled study. Rheumatol Int 35:1863-1872

8. Hsieh L-F, Wei JC-C, Lee H-Y, Chuang C-C, Jiang J-S, Chang K-C (2016) Aerobic capacity and its correlates in patients with ankylosing spondylitis. Int J Rheum Dis 19:490-499

9. O'Dwyer T, O'Shea F, Wilson F (2016) Decreased health-related physical fitness in adults with ankylosing spondylitis: a crosssectional controlled study. Physiotherapy 102:202-209

10. Halvorsen S, Vøllestad NK, Fongen C, Provan SA, Semb AG, Hagen KB et al (2012) Physical fitness in patients with ankylosing spondylitis: comparisons with population controls. Phys Ther 92:298-309

11. O'Dwyer T, Shea FO, Wilson F (2015) Physical activity in spondyloarthritis: a systematic review. Rheumatol Int 35:393-404

12. Chastin SF, Culhane B, Dall PM (2014) Comparison of selfreported measure of sitting time (IPAQ) with objective measurement (activPAL). Physiol Meas 35:2319-2328

13. Loney T, Standage M, Thompson D, Sebire SJ, Cumming S (2011) Self-report vs. objectively assessed physical activity: Which is right for public health? J Phys Act Heal 8:62-70

14. Celis-Morales CA, Perez-Bravo F, Ibañez L, Salas C, Bailey MES, Gill JMR (2012) Objective vs self-reported physical activity and sedentary time: effects of measurement method on relationships with risk biomarkers. PLoS ONEne 7:e36345
15. Paul L, Coulter EH, Cameron S, Mcdonald MT, Brandon M, Cook D et al (2016) Web-based physiotherapy for people with axial spondyloarthritis (WEBPASS) - a study protocol. BMC Musculoskelet Disord 17:1-8

16. Rudwaleit M, Van Der Heijde D, Landewé R, Akkoc N, Brandt J, Chou CT et al (2011) The Assessment of SpondyloArthritis international Society classification criteria for peripheral spondyloarthritis and for spondyloarthritis in general. Ann Rheum Dis 70:25-31

17. Caspersen CJ, Powell KE, Christenson GM (1985) Physical activity, exercise, and physical fitness: definitions and destinctions for health related research. Public Health Rep 100:126-131

18. SBR Network (2012) Letter to the Editor (2012) Standardized use of the terms" sedentary" and "sedentary behaviours". Appl Physiol Nutr Metab 37:540-542

19. Sellers C, Dall P, Grant M, Stansfield B (2016) Agreement of the activPAL3 and activPAL for characterising post ure and stepping in adults and children. Gait Posture 48:209-214

20. Sellers C, Dall P, Grant M, Stansfield B (2016) Validity and reliability of the activPAL3 for measuring posture and stepping in adults and young people. Gait Posture 43:42-47

21. Kozey-Keadle S, Libertine A, Lyden K, Steudenmayer J, Freedson P (2011) Validation of wearable monitors for assessing sedentary behavior. Med Sci Sport Exerc 43:1561-1567

22. Shaw RJ, Iva Č, Deary IJ, Gale CR, Chastin SFM, Dall PM et al (2017) Relationships between socioeconomic position and objectively measured sedentary behaviour in older adults in three prospective cohorts. BMJ Open 7:1-10

23. Garrett S, Jenkinson T, Kennedy LG, Whitelock H, Gaisford P, Calin A (1994) A new approach to defining disease status in ankylosing spondylitis: the Bath Ankylosing Spondylitis Disease Activity Index. J Rheumatol 21:2286-2291

24. Calin A, Garrett S, Whitelock H, Kennedy LG, O'Hea J, Mallorie $P$ et al (1994) A new approach to defining functional ability in ankylosing spondylitis: the development of the Bath Ankylosing Spondylitis Functional Index. J Rheumatol 21:2281-2285

25. Jenkinson TR, Mallorie PA, Whitelock HC, Kennedy LG, Garrett SL, Calin A (1994) Defining spinal mobility in ankylosing spondylitis (AS). The Bath AS Metrology Index. J Rheumatol 21:1694-1698

26. Doward LC, Spoorenberg A, Cook SA, Whalley D, Helliwell PS, Kay LJ et al (2003) Development of the ASQoL: a quality of life instrument specific to ankylosing spondylitis. Ann Rheum Dis 62:20-26

27. Balke B (1963) A simple field test for the assessment of physical fitness. Rep 63-6. Rep Civ Aeromed Res Inst US, pp 1-8

28. Tudor-locke C, Craig CL, Brown WJ, Clemes SA, De CK, Gilescorti B et al (2011) How many steps/day are enough? For adults. Int J Behav Nutr Phys Act 8:79

29. Marshall SJ, Nicaise V, Ji M, Huerta C, Haubenstricker J, Levy SS et al (2013) Using step cadence goals to increase moderateto-vigorous-intensity physical activity. Med Sci Sport Exerc 45:592-602

30. Dunstan DW, Howard B, Healy GN, Owen N (2012) Too much sitting — a health hazard. Diabetes Res Clin Pract 97:368-376

31. Diaz KM, Howard VJ, Hutto B, Colabianchi N, Vena JE, Safford MM et al (2017) Patterns of sedentary behavior and mortality in US middle-aged. Ann Internal Med 167:465-475

32. Pett M (1997) Nonparametric statistics in health care research: statistics for small samples and unusual distributions. SAGE, Thousand Oaks

33. van der Heijde D, Landewé R, Baraliakos X, Van Den BF, Sepriano A, Regel A et al (2017) 2016 update of the ASAS-EULAR management recommendations for axial spondyloarthritis. Ann Rheum Dis 76:978-991 
34. Casanova C, Celli BR, Barria P, Casas A, Cote C, De TJP et al (2011) The 6-min walk distance in healthy subjects: reference standards from seven countries. Eur Respir J 37:150-156

35. Department of Health. Start Active, Stay Active (2011) A report on physical activity for health from the four home countries. Chief Medical Officers, London

36. Dall PM, Skelton DA, Dontje ML, Coulter EH, Stewart S, Cox SR et al (2018) Characteristics of a protocol to collect objective physical activity/sedentary behavior data in a large study : seniors USP (understanding sedentary patterns). J Meas Phys Behav 1:26-31

37. Swinnen TW, Scheers T, Lefevre J, Dankaerts W, Westhovens R, De VK (2014) Physical activity assessment in patients with axial spondyloarthritis compared to healthy controls: a technologybased approach. PLoS ONE 9:e85309

38. Arends S, Hofman M, Kamsma YPT, Van Der VE, Houtman PM, Kallenberg CGM et al (2013) Daily physical activity in ankylosing spondylitis: validity and reliability of the IPAQ and SQUASH and the relation with clinical assessments. Arthritis Res Ther 15:R99

39. Plasqui G, Boonen A, Geusens P, Kroot EJ, Starmans M (2012) Physical activity and body composition in patients with ankylosing spondylitis. Arthritis Res Ther 64:101-107

40. Matthews CE (2005) Calibration of accelerometer outputs for adults. Med Sci Sport Exerc 37:S512-S522

41. Piercy KL, Troiano RP, Ballard RM, Carlson SA, Fulton JE, Galuska DA et al (2018) The physical activity guidelines for Americans. JAMA 320:2020-2028
42. O'Dwyer T, Rafferty T, O'Shea F, Gissane C, Wilson F (2014) Physical activity guidelines: is the message getting through to adults with rheumatic conditions? Rheumatology 53:1812-1817

43. Fongen C, Halvorsen S, Dagfinrud H (2013) High disease activity is related to low levels of physical activity in patients with ankylosing spondylitis. Clin Rheumatol 32:1719-1725

44. Haglund E, Bergman S, Petersson I, Jacobsson L, Strombeck B, Bremander A (2012) Differences in physical activity patterns in patients with spondylarthritis. Arthritis Care Res 64:1886-1894

45. Manning V, Hurley M, Scott D, Bearne L (2012) Are patients meeting the updated physical activity guidelines? Physical activity participation, recommendation, and preferences among inner-city adults with rheumatic diseases. J Clin Rheumatol 18:399-404

46. Rausch Osthoff AK, Niedermann K, Braun J, Adams J, Brodin N, Dagfinrud H et al (2018) 2018 EULAR recommendations for physical activity in people with inflammatory arthritis and osteoarthritis. Ann Rheum Dis 77:1251-1260

Publisher's Note Springer Nature remains neutral with regard to jurisdictional claims in published maps and institutional affiliations. 